\title{
BILANGAN PEROKSIDA PADA MINYAK GORENG PENJUAL GORENGAN DI JALAN RAJAWALI KOTA PALANGKA RAYA
}

\section{Determination of Peroxide Value in Cooking Oil Collected from Fried Snack Seller at Jalan Rajawali Palangka Raya}

\author{
*Suratno \& Ronny Victor Utomo \\ Department of Medical Laboratory Technology, Universitas Muhammadiyah Palangkaraya, Jl. RTA. Milono Km. 1,5, Palangka Raya, \\ Indonesia \\ *e-mail: nono.suratno89@yahoo.com
}

\begin{abstract}
ABSTRAK
Bahaya tingginya bilangan peroksida dapat mengakibatkan keracunan dalam tubuh dan berbagai macam penyakit seperti diare, pengendapan lemak dalam pembuluh darah, kanker dan menurunkan nilai cerna lemak serta destruksi pada vitamin E. Penelitian ini bertujuan untuk mengetahui bilangan peroksida dalam sampel minyak goreng penjual gorengan di Jalan Rajawali Kota Palangka Raya. Jenis penelitian ini menggunakan penelitian deskriptif kuantitatif. Teknik pengambilan sampel dalam penelitian ini menggunakanrandom sampling. Penentuan bilangan peroksida menggunakan metode iodometri. Hasil penelitian menunjukkan bahwa berdasarkan syarat mutu, dari 14 sampel minyak goreng terdapat 78,6\% sampel memenuhi syarat bilangan peroksida dan $21,4 \%$ sampel tidak memenuhi syarat bilangan peroksida. Sampel yang tidak memenuhi syarat yaitu minyak goreng yang telah dipakai lebih dari 5 kali pengulangan penggorengan.
\end{abstract}

Kata kunci: Bilangan Peroksida, Minyak Goreng, Jajanan gorengan, Iodometri

\section{ABSTRACT}

A high peroxide value of used vegetable oil can lead to poisoning in the body and various diseases such as diarrhea, fat deposition in blood vessels, cancer and decrease of digestibility of fat and destruction of vitamin E. This study aims to determine the peroxide values in reused cooking oil on fried snack seller on Jalan Rajawali, Palangka Raya. A quantitative descriptive research design was used in this study.Random sampling technique was used to collect sample. Determination of peroxide value using iodometry method. Results shows that based on quality requirements, from 14 cooking oil samples there were $78.6 \%$ of the samples comply with the peroxide value requirements and $21.4 \%$ of the samples did not comply with the peroxide value requirements. Samples which did not comply with the peroxide value requirements are cooking oil that has been used for more than 5 repetitions.

Keyword: Peroxide Value, Cooking Oil, Fried Snacks, Iodometry

\section{PENDAHULUAN}

Minyak goreng sudah menjadi kebutuhan pokok sebagian masyarakat Indonesia. Kebanyakan masyarakat menggunakan minyak goreng secara berulang-ulang yang menyebabkan penurunan mutu minyak goreng. Bell dan Gillatt (2013) menyatakan bahwa parameter standar untuk penentuan kualitas minyak yaitu seperti kadar uap air, kadar asam lemak bebas, kadar logam berat renik dan bilangan peroksida.

Salah satu parameter penurunan mutu minyak goreng adalah bilangan peroksida.Bilangan peroksida adalah indeks jumlah lemak atau minyak yang telah mengalami oksidasi sehingga terdapat aroma tengik pada minyak karena terbentuknya peroksida. Menurut SNI No.01 3741-2013, syarat bilangan peroksida maksimum adalah 10 mek $\mathrm{O} 2 / \mathrm{kg}$ bahan. Penentuan besarnya bilangan peroksida dapat dilakukan dengan titrasi iodometri. Prinsip titrasi ini adalah senyawa minyak akan dioksidasi oleh kalium iodida (KI) dan iod yang dilepaskan natrium tiosulfat.

Selama proses penggorengan, minyak akan mengalami reaksi degradasi karena panas, udara dan air, yang menyebabkan oksidasi, hidrolisis dan polimerisasi. Hasil reaksi degradasi dalam minyak ini dapat mengurangi kualitas dan berdampak buruk bagi manusia (Bhattacharya et al., 2008). 
Senyawa polimer yang dihasilkan akibat pemanasan yang berulang-ulang dapat menimbulkan gejala keracunan antara lain iritasi saluran pencernaan, pembengkaan organ tubuh, diare, kanker dan depresi pertumbuhan. Selain itu akan timbul rasa tengik akibat oksidasi yang pengaruhnya tidak diharapkan pada bahan pangan yang digoreng. Pengaruh tersebut antara lain mengakibatkan kerusakan gizi, tekstur dan cita rasa (Gunawan et al., 2003).

Jajanan gorengan merupakan salah satu jenis makanan yang digemari masyarakat di Palangka Raya. Jajanan ini sering diolah dengan tidak memperhatikan mutu minyak gorengnya. Penggunaan minyak goreng yang berulang kali dilakukan untuk menekan biaya produksi. Kadar peroksida berlebih dalam minyak goreng yang digunakan berulang kali dapat membahayakan tubuh, khususnya para pengkonsumsi jajanan gorengan di Palangka Raya.

Berdasarkan hal tersebut, penelitian ini bertujuan untuk; (1) mengetahui bilangan peroksida pada sampel minyak yang digunakan oleh penjual gorengan di Jalan Rajawali Kota Palangka Raya, dan (2) mengetahui apakah bilangan peroksida pada sampel minyak goreng yang digunakan oleh para penjual gorengan di Jalan Rajawali Kota Palangka Raya Kalimantan Tengah memenuhi syarat mutu sesuai Standard Nasional Indonesia (SNI) Nomor 01 3741 Tahun 2013.

\section{METODE PENELITIAN}

Jenis penelitian yang digunakan dalam penelitian ini adalah deskriptif dengan pendekatan kuantitatif.Populasi dalam penelitian ini adalah minyak goring pada sejum;aj 15 penjual gorengan di Jalan Rajawali Kota Palangka Raya.Teknik pengambilan sampel yang digunakan adalah random sampling.Sampel yang diambil oleh peneliti adalah 14 sampel minyak goreng dari penjual gorengan di sekitar Jalan Rajawali Kota Palangka Raya sesuai ketentuan Krecjie dan Morgan.Penentuan bilangan peroksida dilakukan di Laboratorium Kimia Analisis, Fakultas Ilmu Kesehatan, Universitas Muhammadiyah Palangkaraya. Data pendukung berupa jumlah pengulangan penggorengan diperoleh dari wawancara terhadap para penjual.

\section{Alat dan Bahan}

Alat yang digunakan dalam penelitian ini seperti: neraca analitik terkalibrasi dengan ketelitian minimal 0,1 mg, labu Erlenmeyer $250 \mathrm{~mL}$, labu ukur 50, 100, 250 dan $1000 \mathrm{~mL}$, pipet ukur 5 dan $10 \mathrm{~mL}$, gelas kimia $50 \mathrm{~mL}$, gelas ukur $50 \mathrm{~mL}$, penangas, buret, spatula, statif dan klem.

Bahan yang digunakan dalam penelitian ini seperti: asam asetat-kloroform 3:2, larutan kanji 1\%, aquades, larutan standar natrium tiosulfat 0,1 $\mathrm{N}$,larutan KI jenuh, kalium iodidat, larutan $\mathrm{HCl} 4 \mathrm{~N}$, larutan KI $20 \%$.

\section{Penetapan Larutan Standar Natrium Tiosulfat}

Sebanyak 0,1 gram kalium iodidat $\left(\mathrm{KIO}_{3}\right)$ kering ditimbang dan dilarutkan ke dalam Erlenmeyer $250 \mathrm{~mL}$ dengan air sulingsebanyak $50 \mathrm{~mL}$, ditambahkan $10 \mathrm{~mL}$ kalium iodida $20 \%$ dan $2,5 \mathrm{~mL}$ $\mathrm{HCl} 4 \mathrm{~N}$, iod yang dibebaskan dititrasi dengan natrium tiosulfat yang akan distandarisasi sampai larutan berwarna kuning, ditambahkan 2 - $3 \mathrm{~mL}$ larutan kanji $1 \%$ dan titrasi dilanjutkan sampai warna biru hilang. Prosedur ini dilakukan secara duplo.

Normalitas natrium tiosulfat dihitung sampai 4 desimal dengan menggunakan rumus:

$\mathrm{N}($ gram ek $/ \mathrm{L})=\frac{\mathrm{W}}{\mathrm{V} \times \mathrm{Eq}}$

Keterangan:

$\mathrm{N}$ : normalitas natrium tiosulfat, dinyatakan dalam gram ekivalen per liter (gram eK/L)

W : bobot kalium iodat, dinyatakan dalam miligram (mg)

$\mathrm{V}$ :volume larutan natrium tiosulfat yang digunakan untuk titrasi, dinyatakan dalam milimeter $(\mathrm{mL})$

Eq : berat equivalen dari kalium iodat

\section{Penentuan Bilangan Peroksida}

Penentuan bilangan peroksida pada minyak goreng menggunakan metode titrasi iodometri menurut SNI Nomor 013741 Tahun 2013 (BSNI, 2013).

Sebanyak $5 \pm 0,005$ gram sampel (W) ditimbang dalam Erlenmeyer $250 \mathrm{~mL}$ yang kering. Sebanyak $50 \mathrm{~mL}$ larutan asam asetat kloroform ditambahkan, Erlenmeyer ditutup dan diaduk hingga 
larutan homogen. Sebanyak 0,5 mL larutan kalium iodida jenuh ditambahkan dengan menggunakan pipet ukur kemudian dikocok selama 1 menit. Sejumlah 30 $\mathrm{mL}$ aquades ditambahkan kemudian Erlenmeyer ditutup dengan segera. Dikocok dan dititrasi dengan larutan natrium tiosulfat $0,1 \mathrm{~N}$ hingga warna kuning hampir hilang, kemudian ditambahkan indikator kanji 0,5 mL dan dilanjutkan pentitrasian, dikocok kuat untuk melepaskan iod dari lapisan pelarut hingga warna biru hilang. Penetapan bilangan peroksida dilakukan secara duplo. Penetapan bilangan peroksida juga dilakukan terhadap minyak goreng kontrol. Bilangan peroksida dalam sampel dihitung dan dinyatakan sebagai miliekivalen $\mathrm{O}_{2}$ per $\mathrm{kg}$ lemak, dengan menggunakan rumus:

Bilangan Peroksida $\left(\right.$ mek $\left.\mathrm{O}_{2} / \mathrm{kg}\right)=\underline{1000 x N x}\left(\mathrm{Vo}^{-} \mathrm{V} 1\right)$ $\mathrm{W}$

Keterangan:

$\mathrm{N}$ : normalitas larutan standar natrium tiosulfat 0,1 $\mathrm{N}$ dinyatakan dalam normalitas $(\mathrm{N})$

Vo : volume larutan natrium tiosulfat $0,1 \mathrm{~N}$ yang diperlukan pada pentitrasian sampel, dinyatakan dalam milimeter $(\mathrm{mL})$

$\mathrm{V} 1$ : volume larutan natrium tiosulfat $0,1 \mathrm{~N}$ yang diperlukan pada pentitrasian blanko, dinyatakan dalam milimeter $(\mathrm{mL})$

W : bobot sampel, dinyatakan dalam gram (g)

\section{HASIL DAN PEMBAHASAN}

Hasil penentuan bilangan peroksida minyak goreng yang dikumpulkan dari penjual gorengan di jalan Rajawali kota Palangka Raya disajikan pada Tabel 1.

Bilangan peroksida digunakan sebagai ukuran sejauh mana reaksi ketengikan telah terjadi selama penyimpanan. Bilangan ini dapat digunakan sebagai petunjuk kualitas dan stabilitas lemak dan minyak (Ekwu \& Nwagu, 2004). Bilangan peroksida juga dapat meningkat selama waktu penyimpanan, suhu dan kontak dengan udara pada sampel minyak (Knothe \&Dunn, 2003).
TABEL 1. Hasil penentuan bilangan peroksida

\begin{tabular}{|c|l|c|c|}
\hline No & \multicolumn{1}{|c|}{ Sampel } & $\begin{array}{c}\text { Bilangan } \\
\text { peroksida } \\
\text { (mek O2/kg) }\end{array}$ & Syarat Mutu* \\
\hline 1 & Sampel A & 7,67 & Memenuhi \\
\hline 2 & Sampel B & 3,8 & Memenuhi \\
\hline 3 & Sampel C & 5,74 & Memenuhi \\
\hline 4 & Sampel D & 5,68 & Memenuhi \\
\hline 5 & Sampel E & 3,78 & Memenuhi \\
\hline 6 & Sampel F & 12,96 & Tidak Memenuhi \\
\hline 7 & Sampel G & 9,31 & Memenuhi \\
\hline 8 & Sampel H & 5,74 & Memenuhi \\
\hline 9 & Sampel I & 5,72 & Memenuhi \\
\hline 10 & Sampel J & 11,45 & Tidak Memenuhi \\
\hline 11 & Sampel K & 3,78 & Memenuhi \\
\hline 12 & Sampel L & 13,2 & Tidak Memenuhi \\
\hline 13 & Sampel M & 5,64 & Memenuhi \\
\hline 14 & Sampel N & 3,75 & Memenuhi \\
\hline
\end{tabular}

*) Memenuhi Syarat Mutu: < 10 mek $\mathrm{O}_{2} / \mathrm{kg}$

Tidak Memenuhi Syarat Mutu: $>10$ mek $\mathrm{O}_{2} / \mathrm{kg}$

Berdasarkan Tabel 1, dapat diketahui bahwa bilangan peroksida terendah yaitu $3,78 \mathrm{mek}_{2} / \mathrm{kg}$ dan nilai angka peroksida tertinggi yaitu 13,2 mek $\mathrm{O}_{2} /$ kg.Peningkatan bilangan peroksida menunjukkan bahwa peroksida terbentuk selama penyimpanan. Selanjutnya, radikal hidroperoksida lipid terbentuk ketika minyak dipanaskan disimpan pada suhu kamar dan digunakan kembali dalam penggorengan (Lamboni et al., 1999).

TABEL 2. Persentase sampel berdasarkan kriteria syarat mutu bilangan peroksida

\begin{tabular}{|l|c|c|}
\hline \multicolumn{1}{|c|}{ Syarat Mutu } & $\begin{array}{c}\text { Jumlah } \\
\text { sampel }\end{array}$ & $\begin{array}{c}\text { Persentase } \\
(\mathbf{\%})\end{array}$ \\
\hline Memenuhi Syarat & 11 & 78,6 \\
\hline Tidak Memenuhi Syarat & 3 & 21,4 \\
\hline
\end{tabular}

Tabel 2 menunjukkan bahwa sebagian besar minyak goreng pada penjual gorengan di sekitar Jalan Rajawali Kota Palangka Raya menggunakan minyak goreng yang memiliki bilangan peroksida memenuhi syarat mutu SNI No.01 3741-2013 yaitu kurang 10 mek $\mathrm{O}_{2} / \mathrm{kg}$.

Penelitian ini menunjukkan bahwa terdapat $21,4 \%$ sampel minyak goreng memiliki bilangan peroksida melebihi syarat mutu. Jika minyak goreng 
tersebut digunakan untuk menggoreng bahan makanan dan dikonsumsi dapat menimbulkan rasa gatal di tenggorokan, hal ini terjadi karena dalam proses penggorengan akan terbentuk akrolein yang disebabkan oleh kerusakan gliserol dengan suhu tinggi. Dilihat dari segi bahaya penggunaannya, minyak goreng berulang-ulang dapat digunakan tidak lebih dari dua kali.

Angka peroksida menunjukkan tingkat kerusakkan minyak karena oksidasi. Tingginya angka peroksida menunjukkan telah terjadi kerusakkan pada minyak (Lempang et al., 2016). Menurut Nurhasnawati et al. (2015) bahwa bilangan peroksida pada minyak goreng yang digunakan oleh penjual gorengan di Jalan A.W. Sjahranie kota Samarinda naik meningkat sebanyak $37,1 \%$ dibanding sebelum proses penggorengan.

Berdasarkan hasil wawancara dengan penjual, diperoleh data pendukung penelitian mengenai jumlah pengulangan penggorengan. Grafik 1 menunjukkan rerata bilangan peroksida berdasarkan jumlah pengulangan penggorengan. Semakin banyak jumlah pengulangan penggorengan maka semakin meningkat bilangan peroksida.

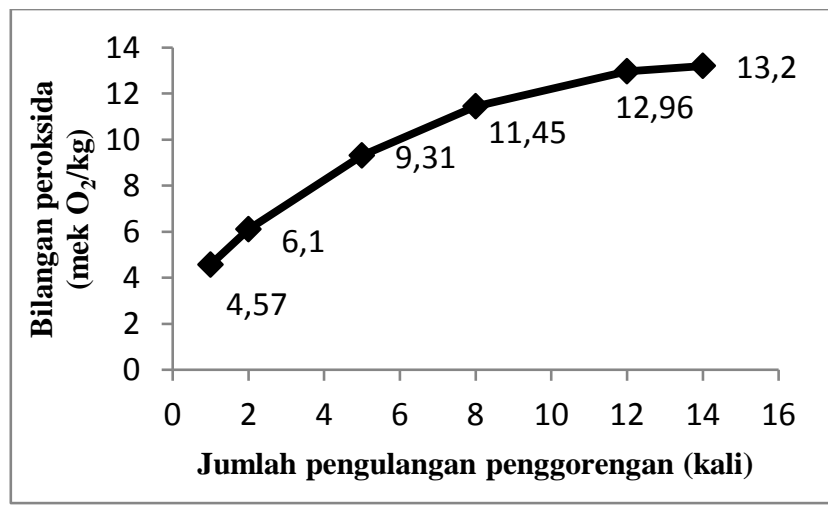

GRAFIK 1. Rerata bilangan peroksida berdasarkan jumlah Pengulangan penggorengan

Menurut penelitian Gunawan et al. (2003) bahwa pada pengulangan penggorengan ke-4 meanyebabkan bilangan peroksida pada minyak goreng kedelai melewati baku mutu. Semakin banyak jumlah pengulangan penggorengan, maka semakin bertambah waktu kontak minyak dengan suhu tinggi. Popa et al. (2017) melaporkan bahwa suhu merupakan faktorpaling berpengaruh terhadap oksidasi minyak bunga matahari, sehingga minyak yang telah digunakan menunjukkan tingkat degradasi oksidatif yang tinggi dimana bilangan peroksida meningkat menjadi $18,32 \mathrm{mek} / \mathrm{kg}$ dalam 60 menit.

\section{KESIMPULAN}

Sebanyak 78,6\% sampel minyak goreng yang digunakan oleh penjual gorengan di Jalan Rajawali Kota Palangka Raya telah memenuhi syarat mutu, sedangkan 21,4\% sampel tidak memenuhi syarat mutu bilangan peroksida. Sampel yang tidak memenuhi syarat yaitu minyak goreng yang digunakan lebih dari 5 kali pengulangan penggorengan.Perlu dilakukan penelitian lebih lanjut mengenai parameter kualitas minyak goreng yang lain.

\section{DAFTAR PUSTAKA}

Badan Standardisasi Nasional Indonesia (BSNI). 2013.SNI 3741: 2013Minyak Goreng. Jakarta, Badan Standar Nasional Indonesia.

Bell, J.R. \&Gillatt, P.N. 1994.Standards to ensure the authenticity of edible oils and fats.Aliment.Nutr. Agric. (FAO), 11, 29-35.

Bhattacharya, Sajilata, Tiwari \& Singhal. 2008. Regeneration of thermally polymerized frying oils with adsorbents. Journal of Food Chemistry, 110: 562-570.

Ekwu, F. C., \& Nwagu, A. 2004. Effect of processing on the quality of cashew nut oils. J. Sci. Agric. Food Tech. Environ. 4: 105-110.

Gunawan, Triatmo, M., \& Rahayu, A. 2003. Analisis Pangan: Penentuan Angka Peroksida dan Asam Lemak Bebas Pada Minyak Kedelai Dengan Variasi Menggoreng. JKSA, 6(3): 13-16.

Knothe, G., \&Dunn, R., 2003. Dependence of oil stability index of fatty compounds on their structure and concentration and presence of metals. J. Am. Oil Chem. Soc. 80: 1021-1026.

Lamboni, C., Ketevi, A., Awaga, K., \& Doh, A. 1999. A Study of Heated Vegetable Oils Used By Street Vendors in Frying Foods in Lome, Togo. Bull. Chem. Soc. Ethiop., 13(2): 173-177. 
Lempang, I.R., Fatimawali, \&Pelealu, N.C. 2016. Uji Kualitas Minyak Goreng Curah dan Minyak Goreng Kemasan di Manado.Pharmacon, 5(4): 155-161.

Nurhasnawati, H., Supriningrum, N., \& Caesariana, N. 2015. Penetapan Kadar Asam Lemak Bebas dan Bilangan Peroksida pada Minyak Goreng yang Digunakan Pedagang Gorengan di Jl. A.W.
Sjahranie Samarinda. Jurnal Ilmiah Manuntung, 1(1): 25-30.

Popa, M., Glevitzky, I., Dumitrel, G-A., Glevitzky, M., \& Popa, D. 2017. Study on Peroxide Values for Different Oils and Factors Affecting the Quality of Sunflower Oil. Scientific Papers. Series E. Land Reclamation, Earth Observation\& Surveying, Environmental Engineering,6: 137-140. 